\title{
A "site" for sore eyes
}

\section{George L. Muntingh, Michelle Viljoen}

Dept of Pharmacology and Clinical Pharmacy, School of Pharmacy, University of the Western Cape, Cape Town, South Africa *Corresponding author, email: gmuntingh@uwc.ac.za

\begin{abstract}
It is known that not all red eyes are caused by infections. Furthermore, not all eye infections will react to antibiotic eye drops. Most cases of conjunctivitis are due to viral causes, do not require antibiotic eye drops and are usually self-limiting. Serious ophthalmic conditions such as infectious keratitis can lead to blindness; it is an emergency that requires specialist treatment. Also infectious endophthalmitis has become more frequent with the use of intravitreal injections. Intravitreal antibiotics are needed to try and prevent visual loss. To ensure therapeutic local exposure ophthalmic antibiotic solutions should be applied frequently into the eye.
\end{abstract}

Keywords: conjunctivitis, eye infection, keratitis, antibiotic

\section{Introduction}

In primary healthcare, eye infections are a common presenting problem. 'Red eye', 'conjunctivitis' and 'corneal ulcer/keratitis' were among the top five problems most commonly referred to ophthalmology departments. ${ }^{1}$

To ensure a good visual outcome for the patient, the medical practitioner should make a prompt diagnosis and start appropriate interventions. Conjunctivitis typically does not threaten vision, but infections of the cornea or inside the eye are serious threats and require immediate referral to an ophthalmologist.

\section{Infectious conjunctivitis}

Conjunctivitis is a common condition that causes dilation of the conjunctival blood vessels and resultant inflammation.

Both viral and bacterial conjunctivitis (Figure 1) present with a red eye and are highly contagious and perhaps not in keeping with William Shakespeare's infamous remark "Take thou some new infection to thy eye, and the rank poison of the old will die." ${ }^{\prime 32}$

Assessment should include checking visual acuity and examination with a torch or slit lamp. Fluorescein drops should be instilled in the conjunctival sac and the eye viewed with the cobalt blue light of the slit lamp, or fundoscope, to rule out any signs of corneal ulceration or infection. A history of cold sores or shingles should be sought and the patient examined for cold sores or a vesicular rash in case the infection is due to herpes simplex or zoster virus. ${ }^{2}$

\section{Viral conjunctivitis}

Viral conjunctivitis is the most common cause of infectious conjunctivitis. This infection is more common in adults than in children. Around $65-90 \%$ of cases are caused by adenovirus. Occasionally, herpes simplex or zoster virus is responsible. Patients can generally be advised that viral conjunctivitis is self-limiting and, as there are no specific treatments, for comfort they can use cold compresses, artificial tears or topical antihistamines. . $^{2,3}$ Antibiotics are not needed, are costly and may increase antibiotic resistance. If there is evidence of herpes simplex or zoster virus then antivirals should be prescribed, such as aciclovir ointment or ganciclovir gel.

When viral conjunctivitis is severe or the patient experiences symptoms after its resolution, the patient should be referred to an ophthalmologist. This is to consider topical steroids and to exclude an immune 'post-viral' keratitis.

\section{Bacterial conjunctivitis}

Although a less frequent cause of conjunctivitis, bacterial conjunctivitis is more common in children. The most common bacteria are Haemophilus influenza, Streptococcus pneumoniae and Staphylococcus aureus. ${ }^{4}$

When compared to placebo, the use of antibiotic eye drops is associated with improved rates of clinical and microbiological remission. ${ }^{4} \mathrm{~A}$ broad-spectrum topical antibiotic is recommended. The medical practitioner can select the most convenient or least expensive option, as there is no clinical evidence suggesting the superiority of any particular antibiotic., ${ }^{3,4}$

The initial treatment recommended by Therapeutic Guidelines: Antibiotic ${ }^{5}$ : 
- Chloramphenicol $0.5 \%$ eye drops, one to two drops every two hours for the first 24 hours, decreasing to six-hourly until the discharge resolves, for up to seven days

- Framycetin sulfate $0.5 \%$ eye drops, 1-2 drops every $1-2$ hours for the first 24 hours, decreasing to eight-hourly until discharge resolves, for up to seven days.

It should be impressed on the patient that the frequency of eye drop installation should be adhered to as this will ensure and maintain a therapeutic concentration and therefore exposure to the antimicrobial in the eye.

Chloramphenicol $1 \%$ eye ointment may be used at bedtime. Gentamicin, tobramycin and quinolone eye drops are not recommended for empiric treatment. If the condition does not improve within five days, the patient should be immediately referred to an ophthalmologist.

Figure 1: Conjunctivitis

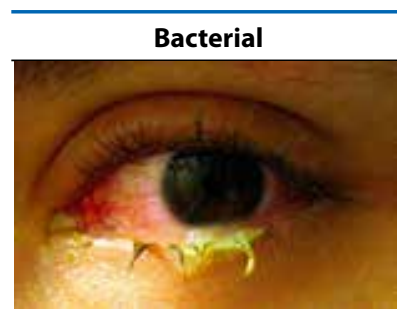

Note discharge in the medial canthus (http://medbox.iiab.me/modules/ en-wikem/wiki/File_Conjunctivitis.html)

\section{Gonococcal conjunctivitis}

Neisseria gonorrhoeae causing conjunctivitis is relatively uncommon but should be considered in neonates and sexually active young adults. If suspected, the medical practitioner should take conjunctival swabs for Gram staining and special culture for Neisseria species. ${ }^{6}$ Patients should be referred immediately to an ophthalmologist. Antibiotic therapy is the recommended treatment and ceftriaxone is the drug of choice. ${ }^{3}$ Additionally, patients should lavage the infected eye with saline and add therapy to cover for Chlamydia. ${ }^{2}$

\section{Chlamydial conjunctivitis}

Most cases of Chlamydial conjunctivitis are unilateral and have concurrent genital infection. Symptoms usually include conjunctival hyperemia, mucopurulent discharge and lymphoid follicle formation. ${ }^{6}$ Patients with symptoms should be referred immediately to an ophthalmologist. Oral antibiotics, such as azithromycin or doxycycline, are effective treatments. ${ }^{7}$

\section{Infectious keratitis}

Infection of the cornea (or microbial keratitis) is an ophthalmic emergency requiring immediate attention as it can progress rapidly. It is a significant cause of corneal blindness ${ }^{8}$ and is one of the most common causes of visual impairment in working age adults. ${ }^{9}$ In the USA, nearly 30000 cases of microbial keratitis are reported annually. ${ }^{10}$
If infectious keratitis is suspected, the medical practitioner should take a history to look for risk factors such as contact lenses, corneal abrasions, physical and chemical trauma, refractive surgery, diabetes, immunosuppressive diseases and topical steroids. ${ }^{10,11}$ The type of infecting organism varies according to the climate and geographical region and the patient's risk factors.

\section{Bacterial keratitis}

Bacterial infection is the most common cause of infectious keratitis. Common causal bacteria include $S$. aureus, coagulasenegative staphylococci, S. pneumoniae and Pseudomonas aeruginosa. ${ }^{10,11}$

P. aeruginosa is the most common microorganism implicated in bacterial keratitis among contact lens wearers. Less commonly, fungi or acanthamoeba can be responsible (Figure 2). ${ }^{12}$ Fungi should be suspected when there is trauma particularly with vegetative matter and is more common in rural environments. Increase suspicion for acanthamoeba, if a patient has been swimming or in a spa while wearing contact

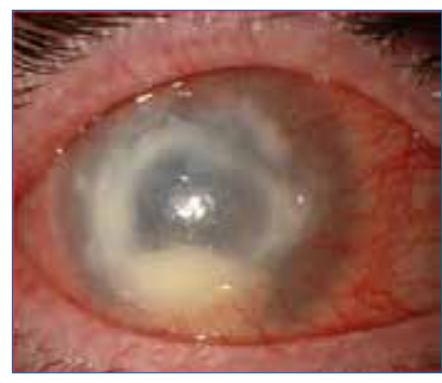

Figure 2: Acanthamoeba Keratitis lenses.

Specific antifungal or anti-acanthamoebal therapy is needed and treatment may last some months and can include regimens of various topical preparations, e.g. NeomycinPolymyxin, B-Gramicidin, polyhexamethylene biguanide (PHMB), chlorhexadine, and voriconazole. Some practitioners recommend oral ketoconazole. ${ }^{13-15}$

The signs and symptoms of bacterial keratitis (Figure 3) can include pain, photophobia, blurred vision, corneal opacity or pus inside eye, or contact lens wearers with red eye or increasing pain. These should be referred promptly to an ophthalmologist for a slit lamp examination and corneal scraping. ${ }^{16}$

The mainstay of treatment is topical antibiotics and options include monotherapy with fluoroquinolones (ciprofloxacin $0.3 \%$ or ofloxacin $0.3 \% 1-2$ drops hourly for 48 hours, then every 4 hours until healed) or some authors prefer fortified aminoglycoside/cephalosporin combinations (fortified cefalotin

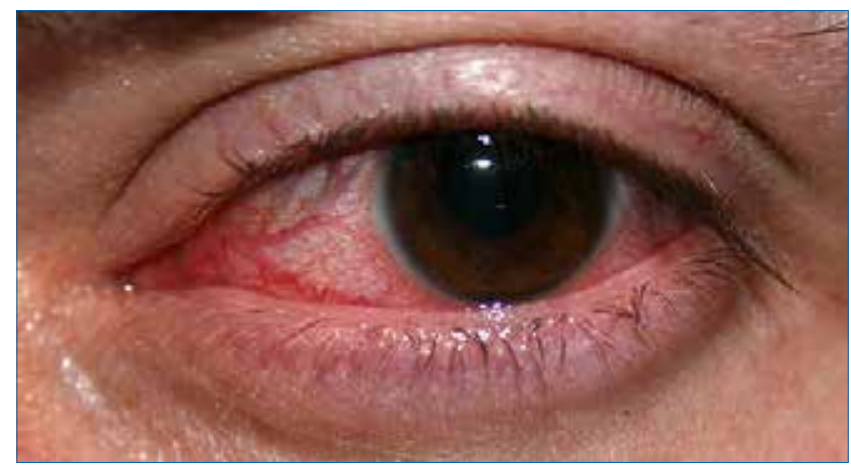

Figure 3: Eye with non-ulcerative sterile keratitis (https://commons.wikimedia.org/wiki/File:Clare-314.jpg) 
$5 \%$ plus gentamicin $0.9 \% 1-2$ drops hourly for 48 hours, then reduce frequency according to treatment response). ${ }^{5}$ These regimens have similar effectiveness but fluoroquinolones reduce the risk of chemical conjunctivitis and ocular discomfort. Compared to ofloxacin, ciprofloxacin increases the risk of white corneal precipitates. ${ }^{17}$ Occasionally, corneal grafting may be needed to eradicate the organism or repair damage.

In primary healthcare, chloramphenicol is the most common first-line antibiotic prescribed for red eye. It is a bacteriostatic, broad-spectrum antibiotic but devoid of activity against P. aeruginosa. ${ }^{18}$ Therefore, primary healthcare providers should not prescribe chloramphenicol when microbial keratitis is suspected as this delays appropriate treatment, with the risk of the patient losing vision or the eye. ${ }^{18,19}$

\section{Herpes simplex keratitis}

Keratitis caused by herpes simplex virus is an important cause of infectious blindness in developed countries. The global incidence of herpes simplex keratitis was calculated at approximately 1.5 million with 40000 new cases of severe monocular visual impairment or blindness per year. ${ }^{20}$ Herpes simplex keratitis can be classified as epithelial, stromal, endothelial or mixed, depending on which layer of the cornea is involved. It may also be considered as primary or recurrent depending on whether it is the patient's first episode. If suspected, the practitioner should ask about a history of cold sores or previous viral keratitis as this can be the first clue to the diagnosis. The clinical features of herpes simplex virus keratitis can be identified on slit lamp examination..$^{21,22}$

Epithelial herpes simplex keratitis typically manifests as a dendritic ulcer. To visualise the ulcer, fluorescein staining and a cobalt blue light are needed (Figure 4).$^{21}$ Preferred treatment is aciclovir ointment five times daily for 14 days. ${ }^{23-25}$

Stromal herpes simplex
keratitis presents with
haze or opacity of the stroma, with or without ulceration, scarring or vascularisation. Endothelial keratitis is characterised by keratitic precipitates on the endothelium and corneal oedema. ${ }^{23}$ Management

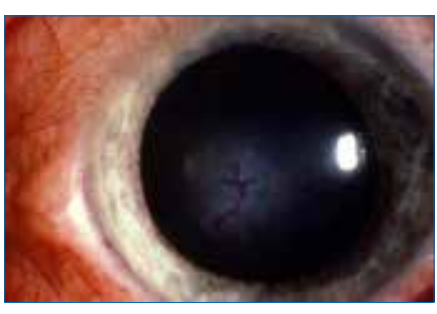

Figure 4: Herpes simplex virus dendritic ulcer

(https://emedicine.medscape.com/ article/1194268-treatment) of stromal and endothelial keratitis involves referral to an ophthalmologist for oral antivirals (aciclovir or valaciclovir), topical steroids and follow-up until the episode has resolved. ${ }^{25}$

\section{Infectious endophthalmitis}

Endophthalmitis is an inflammation of the interior of the eye (Figure 5) and is also an ocular emergency, requiring urgent referral to an ophthalmologist to prevent permanent loss of vision. Endophthalmitis is an uncommon diagnosis but can have devastating visual outcomes. Endophthalmitis may be endogenous or exogenous. Exogenous endophthalmitis is

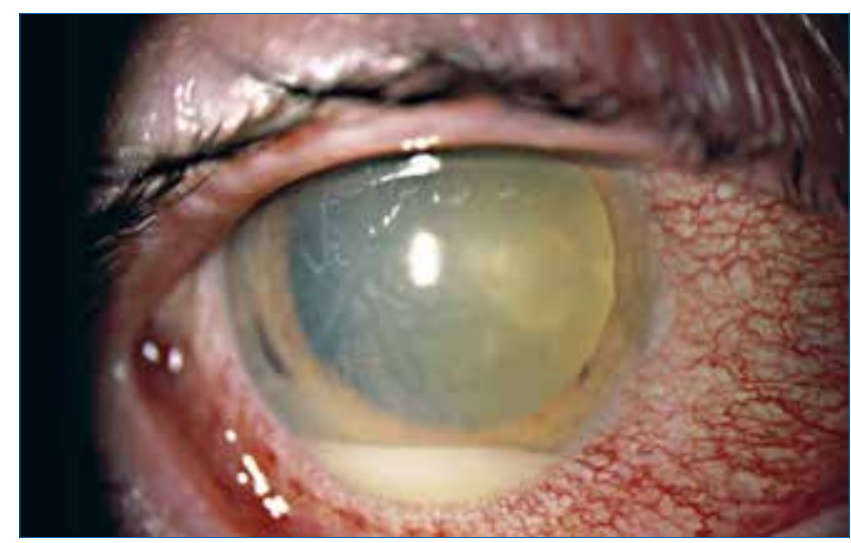

Figure 5: Endophthalmitis

Conjunctival hyperemia with hypopyon in the anterior chamber (https://jamanetwork.com/journals/jamaophthalmology/fullarticle/415216)

caused by introduction of pathogens through mechanisms such as ocular surgery, open-globe trauma, and intravitreal injections. Endogenous endophthalmitis occurs as a result of hematogenous spread of bacteria or fungi into the eye. ${ }^{26}$

Infectious cause is the most common and various bacteria and fungi have been isolated as the cause of the endophthalmitis. The most common microorganisms involved are coagulasenegative staphylococci, S. aureus, streptococci and Gramnegative bacilli, Viruses: Herpes simplex , Fungi: Candida spp., Parasites: Toxoplasma gondii. A minor procedure is needed to obtain samples of vitreous and aqueous humour to isolate the organism. Other causes include penetrating trauma, allergic reaction, and retained intraocular foreign bodies. ${ }^{26}$

Urgent treatment is needed with intravitreal antibiotics such as ceftazidime or vancomycin injected by an ophthalmologist. In some cases vitrectomy may be beneficial to avoid loss of vision. 5,27 If there is a delay in administering intravitreal treatment, give single doses of:

- Oral ciprofloxacin $750 \mathrm{mg}$ (child: $20 \mathrm{mg} / \mathrm{kg}$ up to $750 \mathrm{mg}$ ) plus intravenous vancomycin (adult and child $15 \mathrm{mg} / \mathrm{kg}$ ), or

- Gentamicin (adult and child $5 \mathrm{mg} / \mathrm{kg}$ ) intravenous plus intravenous cefazolin $2 \mathrm{~g}$ (child: $50 \mathrm{mg} / \mathrm{kg}$ up to $2 \mathrm{~g}$ ). ${ }^{5}$

\section{Adverse effects of topical antibiotics}

Typically bacterial infections are treated with antibiotic drops of which some may cause systemic adverse effects. Underestimated is the fact that the volume of the drop produced by commercial dispensers $(25-50 \mu \mathrm{L})$ exceeds the capacity of the conjunctival sac $(10 \mu \mathrm{L})$, therefore a relative large volume of the liquid drains out of the eye. This liquid may be systemically absorbed through different pathways including conjunctiva, nose, lacrimal drainage, pharynx, gastrointestinal tract, aqueous humour, lids, cheeks and inner ocular tissues. However, the risk of systemic absorption is low since the corneal epithelium and conjunctival epithelium act as natural barriers limiting absorption of ocular drug resulting in a bioavailability of $5-10 \% .{ }^{28}$ Some adverse effects can include skin irritation, itching or rash with sulfonamide, sulfacetamide and neomycin. ${ }^{28}$ Fluoroquinolones can cause local 
irritation, stinging, chemosis, conjunctival hyperaemia, corneal precipitations and alteration of taste..$^{29}$

A minimal dose and concentration of the antibiotic must be used in pregnancy to limit systemic absorption. Patients must be advised of punctual occlusion, nasolacrimal pressure and wiping extra liquid to prevent systemic absorption. ${ }^{30}$ Medical practitioners should always refer to the $A B C D$ pregnancy category before prescribing antibiotics to pregnant women. Antibiotics such as chloramphenicol, tobramycin, fluoroquinolones and topical antivirals, e.g. aciclovir, are considered safe to use during pregnancy. ${ }^{31}$

\section{Conclusion}

Patients with eye infections typically present with pain, blurred vision and a red eye. Conjunctivitis is the most common eye infection to present to primary healthcare providers and rarely threatens vision. Corneal infection (keratitis) and endophthalmitis although less common pose a serious risk to vision. If the patient has a history of blurred vision, pain, photophobia, corneal opacity or hypopyon, specialist assessment is urgently called for.

Primary healthcare providers should avoid prescribing topical antibiotics for an eye infection unless the patient has bacterial conjunctivitis. Viral conjunctivitis is common and self-limiting. Urgent referral to an ophthalmologist for microbiological samples and treatment is needed for infectious keratitis and endophthalmitis.

\section{References}

1. Statham MO, Sharma A, Pane AR. Misdiagnosis of acute eye diseases by primary health care providers: incidence and implications. Med J Aust. 2008;189:402-4.

2. Azari AA, Barney NP. Conjunctivitis: a systematic review of diagnosis and treatment. JAMA 2013;310:1721-9. Available from: https://doi.org/10.1001/ jama.2013.280318

3. American Academy of Ophthalmology Cornea/External Disease Panel. Preferred Practice Pattern ${ }^{\ominus}$ Guidelines. Conjunctivitis. San Franciso (CA): American Academy of Ophthalmology; 2013 [accessed 1 May 2018]. Available from: https://www.aao.org/preferred-practice-pattern/conjunctivitis-ppp--2013

4. Sheikh A, Hurwitz B. Antibiotics versus placebo for acute bacterial conjunctivitis. Cochrane Database Syst Rev. 2006;(2):CD001211. Available from: https://doi. org/10.1002/14651858.CD001211.pub2

5. Therapeutic Guidelines. Antibiotic. Version 15. Melbourne: Therapeutic Guidelines Limited; 2014.

6. Morrow GL, Abbott RL. Conjunctivitis. Am Fam Physician. 1998;57:735-46.

7. Katusic $D$, Petricek I, Mandic $Z$, et al. Azithromycin vs doxycycline in the treatment of inclusion conjunctivitis. Am J Ophthalmol. 2003;135:447-51. Available from: https://doi.org/10.1016/S0002-9394(02)02094-9

8. Allan BD, Dart JK. Strategies for the management of microbial keratitis. Br J Ophthalmol. 1995;79:777-86. Available from: https://doi.org/10.1136/ bjo.79.8.777

9. Whitcher JP, Srinivasan M, Upadhyay MP. Corneal blindness: a global perspective. Bull World Health Organ. 2001;79:214-21.

10. Sharma A, Taniguchi J. Review: Emerging strategies for antimicrobial drug delivery to the ocular surface: Implications for infectious keratitis. Ocul Surf. 2017;15:670-9. Available from: https://doi.org/10.1016/j.jos.2017.06.001

11. Green $M$, Apel A, Stapleton F. Risk factors and causative organisms in microbial keratitis. Cornea 2008;27:22-7. Available from: https://doi.org/10.1097/ ICO.0b013e318156caf2
12. Stapleton F, Dart JK, Seal DV, Matheson M. Epidemiology of Pseudomonas aeruginosa keratitis in contact lens wearers. Epidemiol Infect. 1995;114:395-402. Available from: https://doi.org/10.1017/S0950268800052109

13. Maycock NJ, Jayaswal R. Update on acanthamoeba keratitis: diagnosis, treatment, and outcomes. Cornea. 2016;35:713-20. Available from: https://doi. org/10.1097/ICO.0000000000000804

14. Thomas PA, Kaliamurthy J. Mycotic keratitis: epidemiology, diagnosis and management. Clin Microbiol Infect. 2013;19:210-20. Available from: https://doi. org/10.1111/1469-0691.12126

15. Ong HS, Fung SS, Macleod D, Dart JK, Tuft SJ, Burton MJ. Altered patterns of fungal keratitis at a London ophthalmic referral hospital: an eight-year retrospective observational study. Am J Ophthalmol. 2016;168:227-36. Available from: https://doi.org/10.1016/j.ajo.2016.05.021

16. Thomas PA, Geraldine P. Infectious keratitis. Curr Opin Infect Dis. 2007;20:129-41. Available from: https://doi.org/10.1097/QCO.0b013e328017f878

17. McDonald EM, Ram FS, Patel DV, McGhee CN. Topical antibiotics for the management of bacterial keratitis: an evidence-based review of high quality randomised controlled trials. Br J Ophthalmol. 2014;98:1470-7. Available from: https://doi.org/10.1136/bjophthalmol-2013-304660

18. Robaei $D$, Naunton $M$, Watson $S$. Seeing red: over-the-counter chloramphenicol. Clin Experiment Ophthalmol. 2015;43:99-100. Available from: https://doi. org/10.1111/ceo.12497

19. McDerby N, Watson SL, Robaei D, Naunton M. Inappropriate use of topical chloramphenicol results in vision loss. Clin Experiment Ophthalmol. 2015;43:192-3. Available from: https://doi.org/10.1111/ceo.12465

20. Farooq AV, Shukla D. Herpes simplex epithelial and stromal keratitis: an epidemiologic update. Surv Ophthalmol. 2012;57:448-62. Available from: https:// doi.org/10.1016/j.survophthal.2012.01.005

21. Azher TN, Yin XT, Tajfirouz D, Huang AJ, Stuart PM. Herpes simplex keratitis: challenges in diagnosis and clinical management. Clin Ophthalmol. 2017;11:18591. Available from: https://doi.org/10.2147/OPTH.S80475

22. Rowe AM, St Leger AJ, Jeon S, Dhaliwal DK, Knickelbein JE, Hendricks RL. Herpes keratitis. Prog Retin Eye Res. 2013;32:88-101. Available from: https://doi. org/10.1016/j.preteyeres.2012.08.002

23. Guess S, Stone DU, Chodosh J. Evidence-based treatment of herpes simplex virus keratitis: a systematic review. Ocul Surf. 2007;5:240-50. Available from: https:// doi.org/10.1016/S1542-0124(12)70614-6

24. Wilhemus KR. Antiviral treatment and other theraputic interventions for herpes simplex virus epithelial keratitis. Cochrane Database Syst Rev. 2010;CD002898. Available from: https://doi.org/10.1002/14651858.CD002898.pub4

25. White ML, Chodosh J. Herpes simplex virus keratitis: a treatment guideline. 2014 [accessed 1 May 2018]. Available from: www.aao.org/clinical-statement/ herpes-simplex-virus-keratitis-treatment-guideline

26. Keay L, Gower EW, Cassard SD, Tielsch JM, Schein OD. Postcataract surgery endophthalmitis in the United States: analysis of the complete 2003 to 2004 Medicare database of cataract surgeries. Ophthalmology. 2012;119:914-22. Available from: https://doi.org/10.1016/j.ophtha.2011.11.023

27. Durand ML. Bacterial and fungal endophthalmitis. Clin Microbiol Rev. 2017;30:597-613. Available from: https://doi.org/10.1128/CMR.00113-16

28. Farkouh A, Frigo $P$, Czejka M. Systemic side effects of eye drops: a pharmacokinetic perspective. Clin Ophthalmol. 2016;10:2433-41. Available from: https://doi.org/10.2147/OPTH.S118409

29. Thompson AM. Ocular toxicity of fluoroquinolones. Clin Experiment Ophthalmol. 2007;35:566-77. Available from: https://doi. org/10.1111/j.1442-9071.2007.01552.x

30. Chawla S, Chaudhary T, Aggarwal S, Maiti GD, Jaiswal K, Yadav J. Ophthalmic considerations in pregnancy. Med J Armed Forces India. 2013;69:278-84. Available from: https://doi.org/10.1016/j.mjafi.2013.03.006

31. Chung CY, Kwok AK, Chung KL. Use of ophthalmic medications during pregnancy. Hong Kong Med J. 2004;10:191-5.

32. William Shakespeare, Romeo and Juliet. [Accessed 15 Nov 2018]. Available from: http://ccat.sas.upenn.edu/gopher/text/earlymodern/shakespeare/tragedy/ RomeoAndJuliet/RomeoAndJuliet_ACT_I_SCENE_II. 